\title{
Estimating Strain Changes in Concrete during Curing Using Regression and Artificial Neural Network
}

\author{
Kaveh Ahangari, ${ }^{1}$ Zahra Najafi, ${ }^{2}$ Seyed Jamal Sheikh Zakariaee, ${ }^{2}$ and Alireza Arab ${ }^{1}$ \\ ${ }^{1}$ Department of Mining Engineering, Engineering Faculty, Science and Research Branch, Islamic Azad University, Toward Hesarak, \\ End of Ashrafi Esfahani, Poonak Square, P.O. Box 14515/775 \& 14155/4933, Tehran 1477893855, Iran \\ ${ }^{2}$ Department of Geology, Science and Research Branch, Islamic Azad University, Toward Hesarak, End of Ashrafi Esfahani, \\ Poonak Square, P.O. Box 14515/775 \& 14155/4933, Tehran 1477893855, Iran
}

Correspondence should be addressed to Kaveh Ahangari; kaveh.ahangari@gmail.com

Received 14 December 2012; Revised 16 March 2013; Accepted 1 April 2013

Academic Editor: Anaclet Turatsinze

Copyright (C) 2013 Kaveh Ahangari et al. This is an open access article distributed under the Creative Commons Attribution License, which permits unrestricted use, distribution, and reproduction in any medium, provided the original work is properly cited.

Due to the cement hydration heat, concrete deforms during curing. These deformations may lead to cracks in the concrete. Therefore, a method which estimates the strain during curing is very valuable. In this research, two methods of multivariable regression and neural network were studied with the aim of estimating strain changes in concrete. For this purpose, laboratory cylindrical specimens were prepared under controlled situation at first and then vibration wire strain gauges equipped with thermistors were placed inside each sample to measure the deformations. Two different groups of input data were used in which variables included time, environment temperature, concrete temperature, water-to-cement ratio, aggregate content, height, and specimen diameter. CEM I, 42.5 R was utilized in set (I) and strain changes have been measured in six concrete specimens. In set (II) CEM II, $52.5 \mathrm{R}$ was employed and strain changes were measured in three different specimens in which the diameter was held constant. The best multivariate regression equations calculated the determined coefficients at 0.804 and 0.82 for sets (I) and (II), whereas the artificial neural networks predicted the strain with higher $R^{2}$ of 1 and 0.996 . Results show that the neural network method can be utilized as an efficient tool for estimating concrete strain during curing.

\section{Introduction}

Due to increasing use of high-performance concrete, earlyage concrete behavior is a problem of great concern. Concrete at early ages experiences thermal deformations due to the heat generation caused by the cement hydration reactions. These deformations may lead to cracking of concrete. So, one of the most important parameters in studying concrete behavior is deformation or strain [1].

Considering that the major difficulty with early-age concrete monitoring relates to measurement of strains $[2,3]$. Diagnosing the strain during hydration is one of the fundamental problems [1]. Also, measuring concrete strain during curing requires precise instruments and high costs. A practical and accurate measurement of this parameter is faced with major problems [1]. Therefore, utilizing a method that estimates strain during curing is very beneficial.
ASTM C827 is the only standardized test to measure early-age shrinkage of concrete. This test method is limited as only vertical movement can be measured [4].

Jensen and Hansen have devised a method for measuring linear autogenous shrinkage of cement paste [5]. This method uses sealed soft plastic tubes that are partially fixed to a rigid frame. If autogenous shrinkage measurements are done on cement paste alone, they can also be done using a flexible rubber membrane test $[6,7]$.

The most common instrument for strain measuring is the vibrating wire strain gauge.

Each gauge is equipped with a thermistor that can indicate the concrete's temperature [8]. Due to the increase in concrete temperature caused by hydration in the primary stages of curing, the thermal strain of fresh concrete appears as incremental strain (expansion) [9]. When the temperature 
increases the concrete will expand, followed by contraction with cooling [4].

DeLarrard et al. discussed some of the factors that affect the magnitude of drying shrinkage in concrete. These factors include the used aggregate, the water/cement ratio $(w / c)$, the relative humidity, and the specimen size. Concrete with a higher aggregate content has less shrinkage than that with a lower aggregate content [10]. For mixtures made with ordinary Portland cement at W/C ratios of 0.35 and 0.50 , the value of this ratio was found to have relatively little influence on shrinkage. Ultimate shrinkage of pastes and mortars measured on $50 \times 50 \times 400 \mathrm{~mm}$ specimens does not differ much from the real shrinkage measured on $4 \times 8 \times 32 \mathrm{~mm}$ specimens [11].

Researchers have proposed numerous prediction equations for shrinkage during curing such as ones proposed by Bazant and Murphy [12], Branson, ACI-209 equation [13], CEB-FIP-70, 78, 90 equations [14-16], Gardner and Lockman [17], and Sakata [18].

These equations are practical in a sense that dry shrinkage can be predicted from the figures written in the mix proportion table. Furthermore, they are useful for the preliminary study at the design stage because the external factors such as the relative humidity and dimensions, shape of the member, or age are considered. However, the predicted results are not very accurate. Also, Eguchi and Teranishi proposed a prediction equation for dry shrinkage of concrete that is obtained with a two-phase composite model [19].

The aim of this study is to predict the amount of strain during concrete curing regarding the cement type used and with the utilization of time $(h)$, environment temperature, concrete temperature, water-to-cement ratio, diameter, and specimen height as variables. The required data are a result of laboratory experiment.

This research investigated the predictive ability of artificial neural network and regression for estimation of strain changes. Researchers have proposed artificial neural networks because of better predictive ability such as one proposed by Sbartai et al. [20].

Multivariate regression (SPSS software) and artificial neural network (MATLAB) have been used for prediction.

\section{Experiment Procedures}

To predict strain during concrete curing, it is required that the strain gauges inside the concrete measure the strains continuously. The necessary data is obtained from experiments carried out on cylindrical concrete specimens in the Institute of Geotechnical Engineering and Mine Surveying of Technical University of Clausthal, Germany. Three different types of vibrating wire strain gauges and two thermistors were installed in each concrete specimen. A total of 5 strain gauges types were used in this research. The strain gauges were fixed on a steel structure (Figure 1(a)) in such an order that when they are placed inside the cylindrical formwork, they are vertically in line with cylinder axis and are at a 120 degree angle from each other (Figure 1(b)). The concrete specimen, seven days after formwork removal is shown in (Figure 1(c)).
During different stages of concreting, the concrete was compacted appropriately by a manual vibrator. Concrete vibration process was done accurately during concreting. All of the specimens are compacted under the same conditions using handy (manual) vibrator; so the compaction method and compaction procedure were the same for all of them. Therefore, this factor has not any effects on the strain changes of different specimens and this factor is not considered in this study. In fact, the used data are the strain values and their changes after concreting.

The vibrating wire strain gauges were equipped with thermal sensors and the concrete's temperature was measured by strain gauges and thermistors. The measuring began right after specimen concreting and during the curing process strain, and temperature changes were recorded until 30 hours after concreting.

In order to predict the strain more accurately, laboratory data from one type of strain gauge in different concrete specimens were utilized, and strain gauge characteristics are shown in Table 1. Since the temperatures measured by all the sensors were similar, the concrete's measured temperature by the strain gauge's sensor described in Table 1 is considered as concrete temperature.

\section{Experiment Results}

The data employed for predicting strain changes were categorized into two groups depending on the cement type used in the specimens. The two different types of cement used in this study which were produced by the German Deuna Co. are Portland cement (CEM I 42.5) and Portland blast furnace slag cement (CEM II/A-S 52.5). Table 2 shows the combination of these two cements based on the European Standard EN 197-1.

Set I consists of data from 6 experiments carried out on concrete specimens made of I, 42.5 R Portland cement. Characteristics of specimens used in this set are presented in Table 3. For specimens with water-to-cement ratio of 0.50 , $30 \mathrm{~mL}$ plasticizer was used for each $\mathrm{kg}$ of cement.

Set II consists of data from three experiments made on concrete specimens made of II, $52.5 \mathrm{R}$ Portland cement. Table 4 shows the concrete specimen characteristics. The height of the specimens was kept constant at $48 \mathrm{~cm} .27 \mathrm{~mL}$ of plasticizer for each $\mathrm{kg}$ of cement is used in specimens with water-to-cement ratio of 0.58 and $21 \mathrm{~mL}$ of plasticizer in specimens with 0.56 water-to-cement ratio.

Temperature and strain changes during curing for specimens used in sets I and II are presented in Figures 2 and 3.

According to Figures 2 and 3, concrete temperature and strain increased due to the cement hydration heat, after that, concrete temperature and strain decreased.

3.1. Multivariable Regression. In this study, both linear and nonlinear regressions were used to develop equations between strain changes and input variables. The stepwise variable selection procedure was applied to prepare equations. At the first step, we tried to establish a general relation for both concrete types, but the relation has not a high accuracy $\left(R^{2}\right)$. 


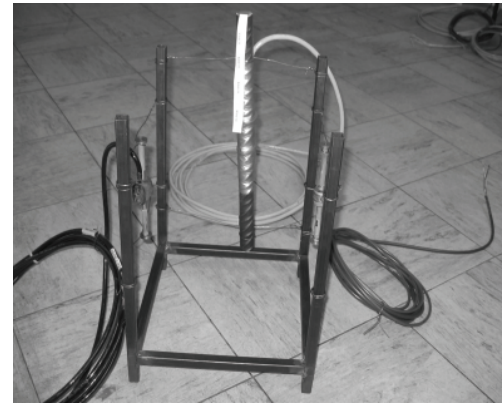

(a)

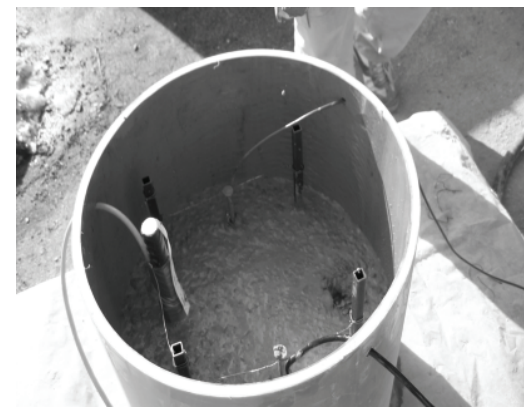

(b)

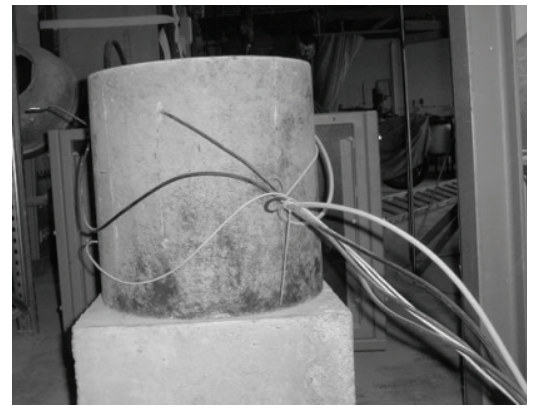

(c)

FIGURE 1: Stages of laboratory specimen instrumentation and concreting: (a) fixing the strain gauges on the steel structure; (b) placement of instruments inside the formwork and concreting; and (c) specimen after formwork removal.

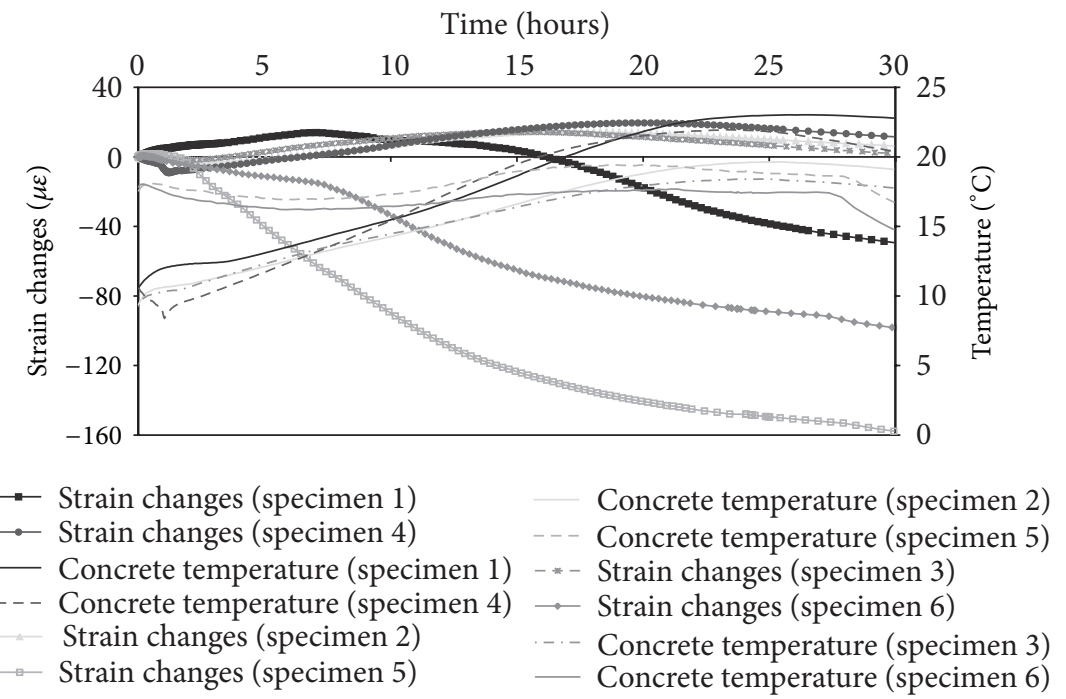

Figure 2: Temperature and strain changes during curing for specimens used in set I for data analysis and results.

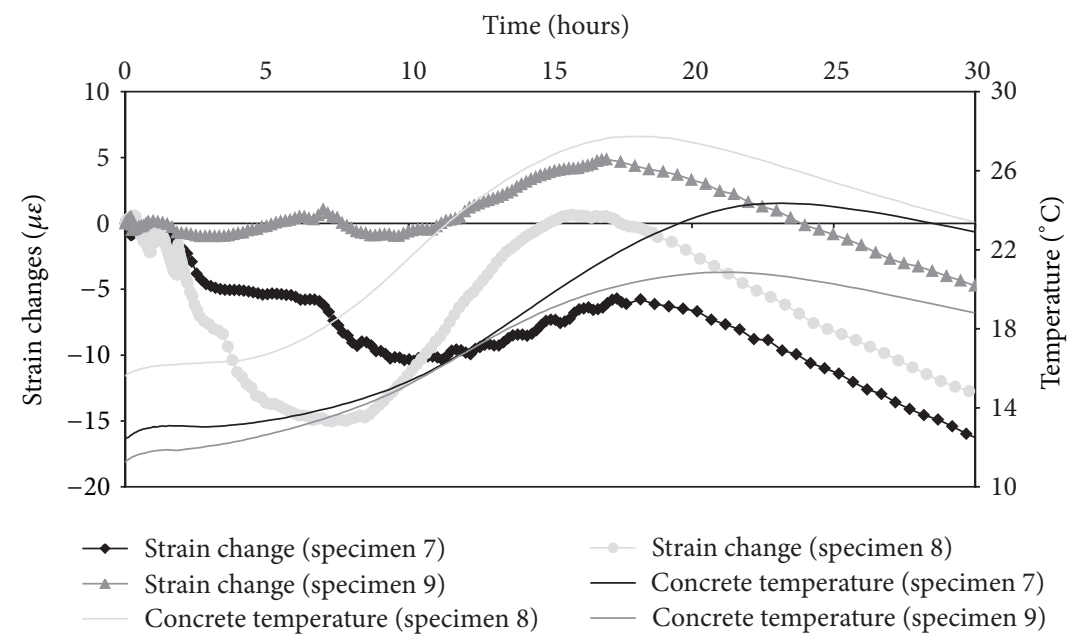

FIgURE 3: Temperature and strain changes during curing for specimens used in set II. 
TABLE 1: Utilized strain gauge characteristics.

\begin{tabular}{lccccc}
\hline Instrument type & Model & Measurement range & Measurement accuracy & Length & Manufacturer \\
\hline Concrete strain gauge & VCE-4200 & $3000 \mu \varepsilon$ & $1 \mu \varepsilon$ & $155 \mathrm{~mm}$ & Geokon \\
\hline
\end{tabular}

TABLE 2: Cement combination based on DIN EN 197-1 [21].

\begin{tabular}{|c|c|c|c|c|c|}
\hline Cement type & Cement name/main composition & Portland cement clinker & Slag \% & Subsidiary compound \% & Indication \\
\hline $\mathrm{I}$ & Portland cement & I & $95-100$ & - & CEM I 42.5 \\
\hline II & Portland blast furnace slag cement & II/A-S & $80-94$ & $6-20$ & CEM II 52.5 \\
\hline
\end{tabular}

TABLE 3: Characteristics of experimental specimens for set I.

\begin{tabular}{|c|c|c|c|c|c|c|}
\hline Specimen no. & $w / c$ & $W(\mathrm{~kg})$ & Cement (kg) & Diameter $(\mathrm{cm})$ & Height $(\mathrm{cm})$ & Aggregate $(\mathrm{kg})$ \\
\hline 1 & 0.50 & 7.0 & 14.0 & 46 & 48 & 91.458 \\
\hline 2 & 0.50 & 7.0 & 14.0 & 30 & 48 & 91.458 \\
\hline 3 & 0.50 & 7.0 & 14.0 & 20 & 48 & 91.458 \\
\hline 4 & 0.67 & 5.16 & 7.7 & 30 & 48 & 44.000 \\
\hline 5 & 0.50 & 7.0 & 14 & 30 & 25 & 87.772 \\
\hline 6 & 0.50 & 7.0 & 14 & 20 & 25 & 87.772 \\
\hline
\end{tabular}

TABLE 4: Characteristics of experimental specimens for set II.

\begin{tabular}{lcccccc}
\hline Specimen no. & $w / c$ & $w(\mathrm{~kg})$ & $C(\mathrm{~kg})$ & Diameter $(\mathrm{cm})$ & Height $(\mathrm{cm})$ & 48 \\
\hline 7 & 0.58 & 8.12 & 14 & 46 & 48 & 91.458 \\
8 & 0.67 & 10.32 & 15.4 & 46 & 38.188 \\
9 & 0.56 & 6.16 & 11 & 30 & 48 & 71.854 \\
\hline
\end{tabular}

Therefore, according to the used cement type, two different sets were used for strain change prediction:

(I) concrete specimens made of CEM I, 42.5 R;

(II) concrete specimens made of CEM II, $52.5 \mathrm{R}$.

The statistical parameters of input variables for sets I and II are shown in Tables 5 and 6.

3.1.1. Estimated Equations for Strain during the Curing of Concrete Made of CEM I, 42.5 R. By using the least square mathematical method, the intercorrelations of time $(h)$, environment temperature, concrete temperature, water-to-cement ratio (w/c), aggregate content, specimen diameter, and height with the amount of strain change were calculated as -0.376 , $0.535,-0.274,0.226,-0.165,0.126$, and 0.695 , respectively. Results show that with the increase of environment temperature and specimen height, strain in concrete can rise. The other variables are not significant.

Both the linear and nonlinear equations between input variables and strain changes were studied and their determined correlation coefficients $\left(R^{2}\right)$ were close. Because the difference distribution between the predicted strain changes and actual values is more accurate in the linear equation than nonlinear equation, the linear equation was selected as follows:

$$
\begin{aligned}
\varepsilon= & -282.299-3.582 t+4.954 T_{\text {out }} \\
& +6.946 T-1.453 d+3.724 h \quad R^{2}=0.804,
\end{aligned}
$$

in which $t, T, T_{\text {out }}, d$, and $h$ are time $(h)$, concrete temperature $\left({ }^{\circ} \mathrm{C}\right)$, environment temperature $\left({ }^{\circ} \mathrm{C}\right)$, concrete specimen diameter $(\mathrm{cm})$, and height $(\mathrm{cm})$, respectively.

Equation (1) shows that $R^{2}=0.804$ and $\mathrm{MSE}=1.47$.

Difference distribution between measured strain changes from (1) and actual strain changes is shown in Figure 4. Results show that (1) can have a significant estimation of strain changes during curing for concrete made of CEM I, $42.5 \mathrm{R}$.

3.1.2. Estimated Equations for Strain during the Curing of Concrete Made of CEM II, 52.5 R. By using the least square mathematical method, the intercorrelations of time $(h)$, environment temperature, concrete temperature, water-to-cement ratio, aggregate content, and diameter with the amount of strain change were calculated $-0.242,0.181,-0.211,-0.298$, -0.559 and -0.555 respectively. Results show that with the increase of aggregate content and specimen diameter, strain change in concrete can decreases. The other variables are not significant.

The linear equation between input variables and strain is as follows:

$$
\begin{aligned}
\varepsilon= & -73.146-0.784 t+1.861 T_{\text {out }} \\
& +1.157 T-2.324 d+1.451 g \quad R^{2}=0.692 .
\end{aligned}
$$

Also, the nonlinear equation between parameters is

$$
\begin{aligned}
\varepsilon= & -206.153-2.065 t+0.855 T_{\text {out }}+23.451 T-3.077 d \\
& +2.031 g+0.09 t^{2}-1.197 T^{2}-0.002 t^{3}+0.021 T^{3} \quad R^{2}=0.82,
\end{aligned}
$$


TABLE 5: The range of variables for set I.

\begin{tabular}{|c|c|c|c|c|c|}
\hline Variable (\%) & Minimum & Maximum & Mean & Standard deviation & No. of data \\
\hline Time (hour) & 0.00 & 30.933 & 10.60 & 9.317 & 939 \\
\hline Environment temperature $\left({ }^{\circ} \mathrm{C}\right)$ & 11.23 & 20.670 & 17.39 & 1.330 & 939 \\
\hline Concrete temperature $\left({ }^{\circ} \mathrm{C}\right)$ & 8.39 & 23.030 & 15.63 & 3.800 & 939 \\
\hline Water/cement ratio (\%) & 50.00 & 67.000 & 53.00 & 6.000 & 939 \\
\hline Aggregate weight (kg) & 44.00 & 91.458 & 82.27 & 17.430 & 939 \\
\hline Diameter of specimen $(\mathrm{cm})$ & 20.00 & 46.000 & 30.00 & 9.000 & 939 \\
\hline Height of specimen $(\mathrm{cm})$ & 25.00 & 48.000 & 40.00 & 10.000 & 939 \\
\hline
\end{tabular}

TABLE 6: The range of variables for set II.

\begin{tabular}{|c|c|c|c|c|c|}
\hline Variable (\%) & Minimum & Maximum & Mean & Standard deviation & No. of data \\
\hline Time (hour) & 0.00 & 30.98 & 9.82 & 8.37 & 498 \\
\hline Environment temperature $\left({ }^{\circ} \mathrm{C}\right)$ & 12.95 & 17.88 & 16.05 & 1.07 & 498 \\
\hline Concrete temperature $\left({ }^{\circ} \mathrm{C}\right)$ & 11.24 & 27.74 & 17.76 & 4.60 & 498 \\
\hline Water/cement ratio (\%) & 56.00 & 67.00 & 61.00 & 4.90 & 498 \\
\hline Aggregate weight (kg) & 71.85 & 91.46 & 84.56 & 8.19 & 498 \\
\hline Diameter of specimen $(\mathrm{cm})$ & 30.00 & 46.00 & 41.00 & 7.00 & 498 \\
\hline
\end{tabular}

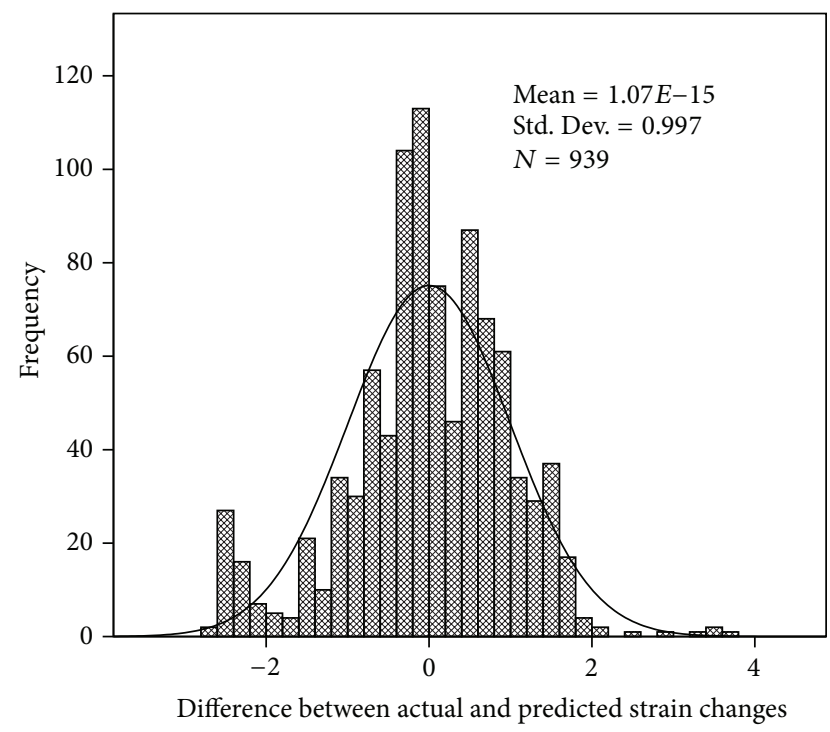

FIGURE 4: Distribution of the difference between actual strain change values and predicted strain change values obtained from multivariate regression (1) for set I (CEM I, 42.5 R).

in which $t, T, T_{\text {out }}, d$, and $g$ are time $(h)$, concrete temperature $\left({ }^{\circ} \mathrm{C}\right)$, environment temperature $\left({ }^{\circ} \mathrm{C}\right)$, concrete specimen diameter $(\mathrm{cm})$, and aggregate amount $(\mathrm{kg})$, respectively.

Equations (2) and (3) show that MSE $=0.305$ and MSE $=$ 0.12 , respectively.

Difference distribution between measured strain changes from (3) and actual strain changes is shown in Figure 5. Results show that (3) can have a significant estimation of strain changes during curing for concrete made of CEM II, $52.5 \mathrm{R}$.

3.2. Artificial Neural Network Procedure. Among the existing numerous neural networks (NNs) paradigms, feedforward artificial neural networks (FANNs) are the most popular due to their flexibility in structure, good presentational capabilities, and large number of available training algorithms [2224].

The basic structure of a multilayer feedforward network model can be made of one input layer, one or more hidden layers, and one output layer [25].

Neural network training can be made more efficient by specific preprocessing. In this research, all the input and output parameters were preprocessed by normalizing inputs and targets; therefore, in the preprocessing stage their mean and standard deviation are 0 and 1 , respectively:

$$
N_{p}=\frac{\left(A_{p}-\operatorname{mean} A_{p s}\right)}{\operatorname{std} A_{p}},
$$

in which $A_{p}$ is actual parameter, mean $A_{p s}$ is actual parameters mean, std $A_{p}$ is actual parameters standard deviation, and $N_{p}$ is normalized parameter [26].

In this part of the study, ANN model is presented to predict strain changes during curing. Multilayer feed forward network models have been trained with BP (back propagation) training algorithm.

Several training algorithms exist, but back propagation (BP) commonly provides satisfactory results. BP is a gradient descent algorithm which consists of changing network parameters (weights and bias) according to the negativity of the error function [27].

Different neural networks were designed and the best parameters value was obtained by trial and error. However, the main aim is to acquire a neural network with the smallest dimensions and the least errors. The most appropriate results have been obtained from chosen network models in which hyperbolic tangent sigmoid and linear functions were used as an activation function for the hidden and output layer neurons. According to (1) and (2), the selected variables were determined as the best variables for predicting strain changes. 


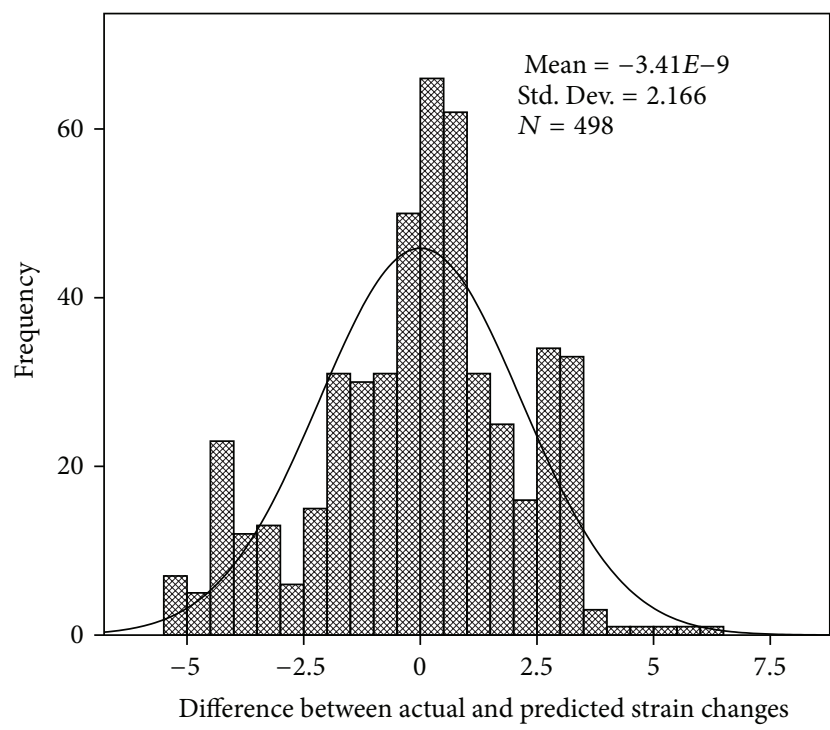

FIGURE 5: Distribution of the difference between actual strain change values and predicted strain change values obtained from multivariate regression (3) for set II (cement type 2, $52.5 \mathrm{R}$ ).

Therefore, those variables were used as inputs (I and II) to ANN for the improvement of strain changes prediction which are listed in Table 7.

The data in each model were separated into three sets: training, validation, and test in which the test set was used after training.

The validation and training process were stopped after 114 and 108 epochs for models I and II, respectively.

The performance functions used are the mean square error (MSE), the average squared error between the network predicted outputs and the target outputs, and the relative error of the training and testing performances that are shown in Table 8.

The correlation coefficients for the validation and training stages are presented in Table 9.

Figures 6 and 7 show a graphical comparison of the determined experimental strain changes and those predicted by artificial neural network in the test process for models I and II.

Distributions of the difference between predicted strain changes by ANN and actual values in models I and II are presented in Figures 8 and 9.

ANN models evaluate strain changes with higher $R^{2}$ and lower MSE. It was observed that strain changes prediction using ANN procedure could be much acceptable and satisfactory.

\section{Conclusions}

(i) Strain changes in concrete during curing by experimenting on cylindrical concrete specimens under controlled situations were studied in which the concrete strain was measured using vibration wire strain gauges equipped with thermistors. Data recording

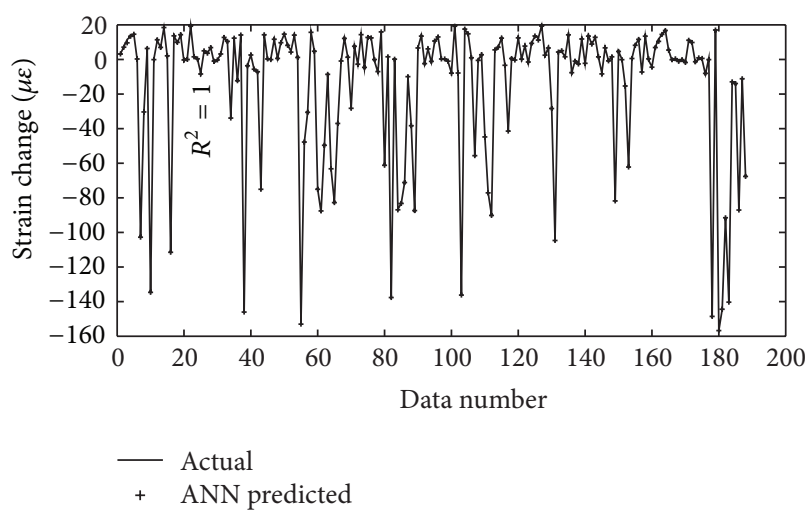

FIGURE 6: Graphical comparison of experimental Strain changes with those predicted by ANN for model I in the test process (for CEM I, 42.5 R).

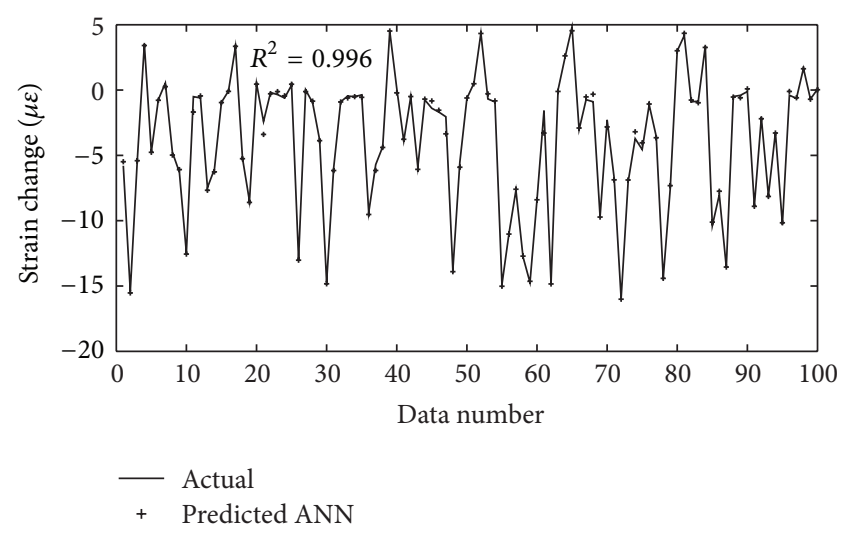

FIGURE 7: Graphical comparison of experimental Strain changes with those predicted by ANN for model II in the test process (for CEM II, 52.5 R).

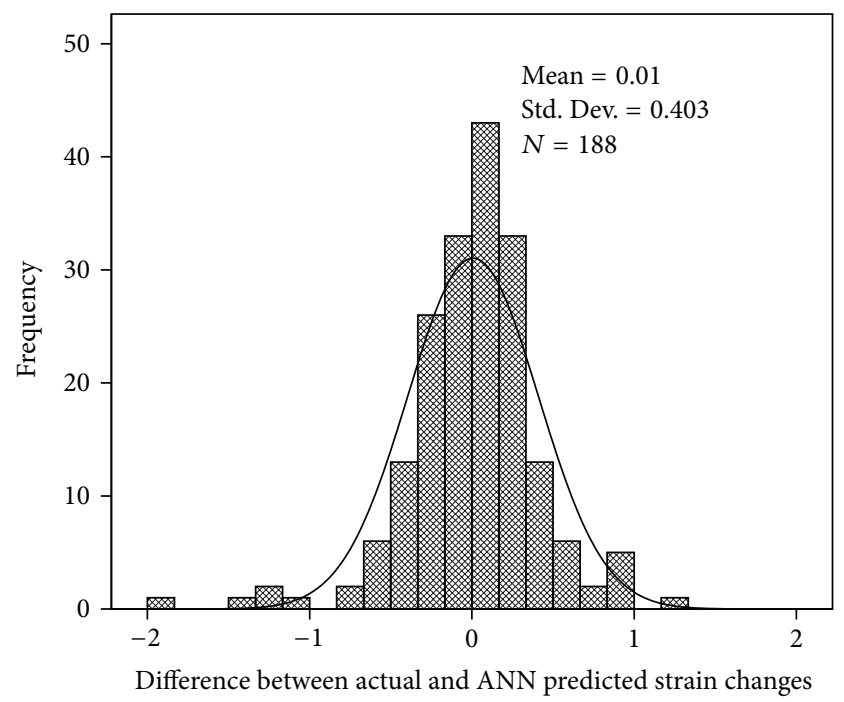

FIGURE 8: Distribution of the difference between predicted strain changes obtained from ANN and actual values for model I. 
TABLE 7: Details of ANN models ( $I$ : number of input nodes, $J$ : number of nodes in the first hidden layer, and $K$ : number of nodes in the second hidden layer).

\begin{tabular}{lcccccc}
\hline Model & \multicolumn{1}{c}{ Input sets } & Training set size & Testing set size & Validation set size & $I$ & $J$ \\
\hline I & $t, T_{\text {out }}, T, d, h($ set I $)$ & 563 & 188 & 188 & 4 & 6 \\
II & $t, T_{\text {out }}, T, w / c, g($ set II $)$ & 299 & 100 & 99 & 5 \\
\hline
\end{tabular}

TABLE 8: MSE and the relative error of the training and testing performances for ANN models.

\begin{tabular}{lcccc}
\hline \multirow{2}{*}{ Model } & \multicolumn{2}{c}{ Training stage } & \multicolumn{2}{c}{ Test stage } \\
& MSE & Relative error (\%) & MSE & Relative error (\%) \\
\hline I & 0.0000633 & $5 \%$ & 0.000033 & $3 \%$ \\
II & 0.00113 & $3 \%$ & 0.00414 & $11 \%$ \\
\hline
\end{tabular}

TABLE 9: Statistical analysis of predicted strain and generalization performance of ANN-based models.

\begin{tabular}{lcc}
\hline Model & $\begin{array}{c}\text { Performance of ANN models } \\
\text { Validation stage } \\
\text { Correlation coefficient }\end{array}$ & $\begin{array}{c}\text { Performance of ANN models } \\
\text { Training stage } \\
\text { Correlation coefficient }\end{array}$ \\
\hline I & 1 & 1 \\
II & 0.999 & 0.997 \\
\hline
\end{tabular}

began right after specimen concreting and continued until 30 hours after.

(ii) Strain changes during curing are investigated using time, environment temperature, concrete temperature, water-to-cement ratio, diameter, and specimen height as variables.

(iii) Models I and II were used for concrete which were prepared with I, 42.5 R and II, 52.5 R cement, respectively. The models were utilized for estimating strain changes using stepwise regression and artificial neural network methods.

(iv) The intercorrelation between input variables and strain changes showed that the effect of environment temperature and specimen height parameters on strain changes in concrete when I, $42.5 \mathrm{R}$ cement is used is higher and increases with the increase of the mentioned parameters. Parameters of specimen diameter and aggregate content in the concrete when II, $52.5 \mathrm{R}$ cement is used have large effect on concrete strain. With the increase of these parameters, strain changes in concrete decrease.

(v) The equations obtained from multivariable regression can estimate strain changes with correlation coefficients $\left(R^{2}\right)$ of 0.804 and 0.82 for models I and II.

(vi) The artificial neural network procedure can predict strain changes with correlation coefficients of 1 and 0.996 for the input models of I and II, respectively.

(vii) ANN models evaluate strain changes with lower MSE.

(viii) The ANN obtained results are more accurate than those of multivariate regression.

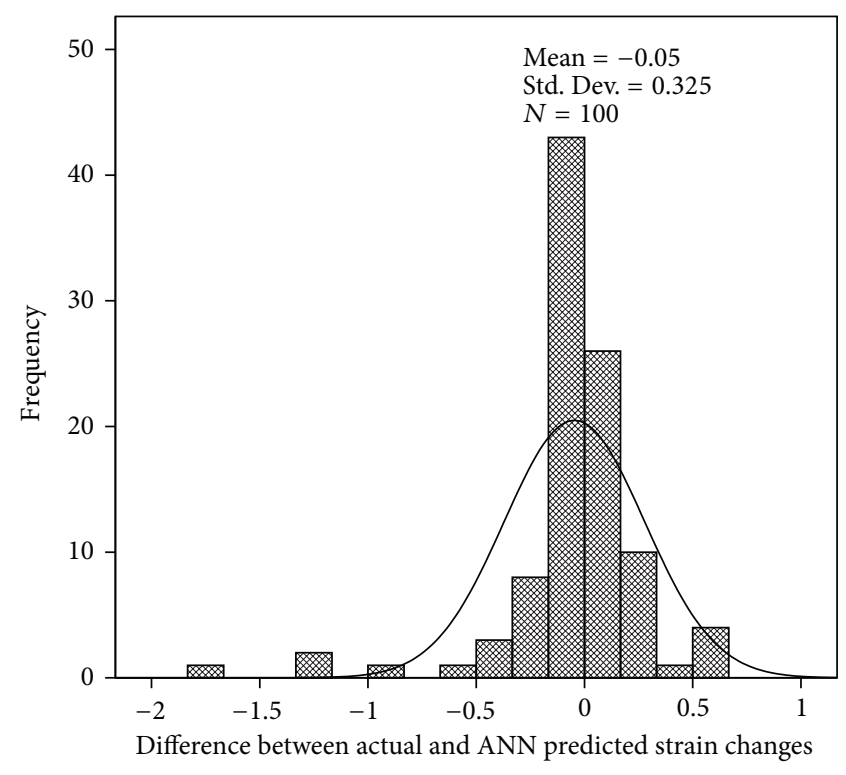

FIGURE 9: Distribution of the difference between predicted strain changes obtained from ANN and actual values for model II.

(ix) Results show that artificial neural network can be applied as a reliable method to predict strain changes in concrete during curing, and ANN models exhibit better predictive ability than regression.

\section{Conflict of Interests}

Hereby, the authors declare that this paper was just a contribution to advancement of science and they just used SPSS and MATLAB software as the mathematical methods for prediction. They as authors do not have a direct financial relation with the commercial identities mentioned in their paper (SPSS and MATLAB software).

\section{References}

[1] M. Azenha, R. Faria, and D. Ferreira, "Identification of early-age concrete temperatures and strains: monitoring and numerical simulation," Cement and Concrete Composites, vol. 31, no. 6, pp. 369-378, 2009.

[2] M. Azenha, Behaviour of concrete at early ages. Phenomenology and thermo- mechanical analysis [M.S. thesis], Faculty of Engineering of the University of Porto, Porto, Portugal, 2004.

[3] R. Faria, M. Azenha, and J. A. Figueiras, "Modelling of concrete at early ages: application to an externally restrained slab," Cement and Concrete Composites, vol. 28, no. 6, pp. 572-585, 2006. 
[4] E. E. Holt, "Early age autogenous shrinkage of concrete. Espoo 2001. Technical Research. Centre of Finland," VTT Publications, no. 446, pp. 2-184, 2001.

[5] O. M. Jensen and P. F. Hansen, "A dilatometer for measuring autogenous deformation in hardening portland cement paste," Materials and Structures, vol. 28, no. 7, pp. 406-409, 1995.

[6] H. Justnes, A. van Gemert, F. Verboven, and E. J. Sellevold, "Total and external chemical shrinkage of low w/c ratio cement pastes," Advances in Cement Research, vol. 8, no. 31, pp. 121-126, 1996.

[7] T. A. Hammer, "Test methods for linear measurement of autogenous shrinkage before setting," in Autogenous Shrinkage of Concrete, Ei-ichi Tazawa, Ed., pp. 143-154, E \& FN Spon, London, UK, 1999.

[8] Geokon Incorporated, "Instruction manual model 4200/4202/ 4202/4210 vibrating wire strain gages, 1-2," 2004.

[9] H. Weigler and S. Karl, Junger Beton, Beanspruchung-FestigkeitVerformung, vol. 40, Betonwerk Fertigteil-Technik, Munich, Germany, 1974.

[10] D. W. Mokarem, R. M. Meyerson, and R. E. Weyers, "Development of concrete shrinkage performance specifications," Final Contract Report 04-CR1, Virginia Transportation Research Council (VTRC), Charlottesville, Va, USA, 2003.

[11] B. Bissonnette, P. Pierre, and M. Pigeon, "Influence of key parameters on drying shrinkage of cementitious materials," Cement and Concrete Research, vol. 29, no. 10, pp. 1655-1662, 1999.

[12] Z. P. Bazant and W. P. Murphy, "Creep and shrinkage prediction model for analysis and design of concrete structures-model B3," Materiaux et Constructions, vol. 28, no. 180, pp. 357-365, 1995.

[13] ACI Committee 209, Prediction of Creep, Shrinkage and Temperature Effects in Concrete Structures, vol. SP-76, American Concrete Institute, Farmington Hills, Mich, USA, 1982.

[14] CEB-FIP, International Recommendations for the Design and Construction of Concrete Structures, Comite Europeen du beton-Federation International de la Precontrainte, Cement and Concrete Association, London, UK, 1970.

[15] CEB-FIP, Model Code for Concrete Structures (International System of Unified Standard Codes of Practice For Structures), Comite Euro-International du Beton, Lausanne, Switzerland, 1978.

[16] CEB-FIP, Model Code, Comite Euro-International du Beton, Lausanne, Switzerland; Thomas Telford Services, London, UK, 1990.

[17] N. J. Gardner and M. J. Lockman, "Design provisions for drying shrinkage and creep of normal-strength concrete," ACI Materials Journal, vol. 98, no. 2, pp. 159-167, 2001.

[18] K. Sakata, "Prediction of concrete creep and shrinkage. Creep and shrinkage of concrete," in Proceedings of the 5th International RILEM Symposium, 1993.

[19] K. Eguchi and K. Teranishi, "Prediction equation of drying shrinkage of concrete based on composite model," Cement and Concrete Research, vol. 35, no. 3, pp. 483-493, 2005.

[20] Z. M. Sbartai, S. Laurens, S. M. Elachachi, and C. Payan, "Concrete properties evaluation by statistical fusion of NDT techniques," Construction and Building Materials, vol. 37, pp. 943950, 2012.

[21] W. Hansen, "Constitutive model for predicting ultimate drying shrinkage of concrete," Journal of the American Ceramic Society, vol. 70, no. 5, pp. 329-332, 1987.

[22] C. T. Leondes, Neural Network Systems Techniques and Applications: Algorithms and Architectures, Academic Press, New York, NY, USA, 1998.
[23] R. P. Lippmann, "An introduction to computing with neural nets," IEEE ASSP Magazine, vol. 4, no. 2, pp. 4-22, 1987.

[24] D. Sarkar, "Methods to speed up error back-propagation learning algorithm," ACM Computing Surveys, vol. 27, no. 4, pp. 519542, 1995.

[25] F. Ozcan, C. D. Atis, O. Karahan, E. Uncuoglu, and H. Tanyildizi, "Comparison of artificial neural network and fuzzy logic models for prediction of long-term compressive strength of silica fume concrete," Advances in Engineering Software, vol. 40, no. 9, pp. 856-863, 2009.

[26] H. Demuth and M. Beale, Neural Network Toolbox for Use with MATLAB, Handbook, 2002.

[27] Z. Dahou, Z. M. Sbartaï, A. Castel, and F. Ghomari, "Artificial neural network model for steel-concrete bond prediction," Engineering Structures, vol. 31, no. 8, pp. 1724-1733, 2009. 

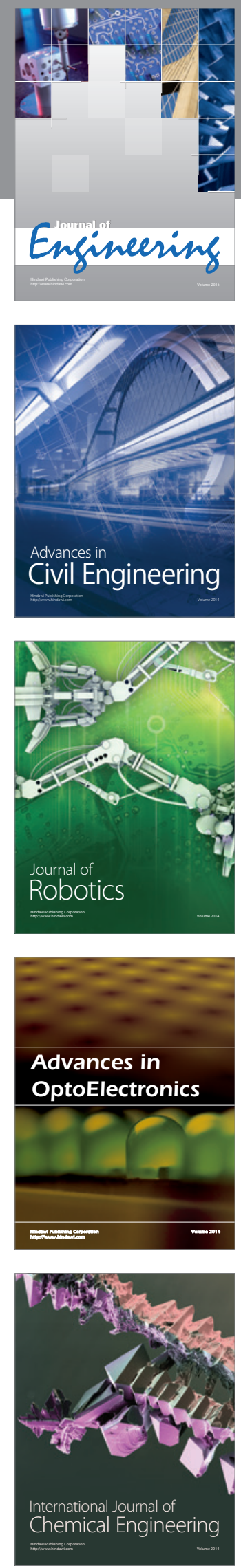

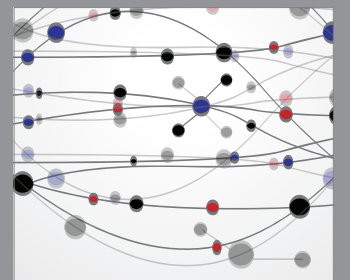

The Scientific World Journal
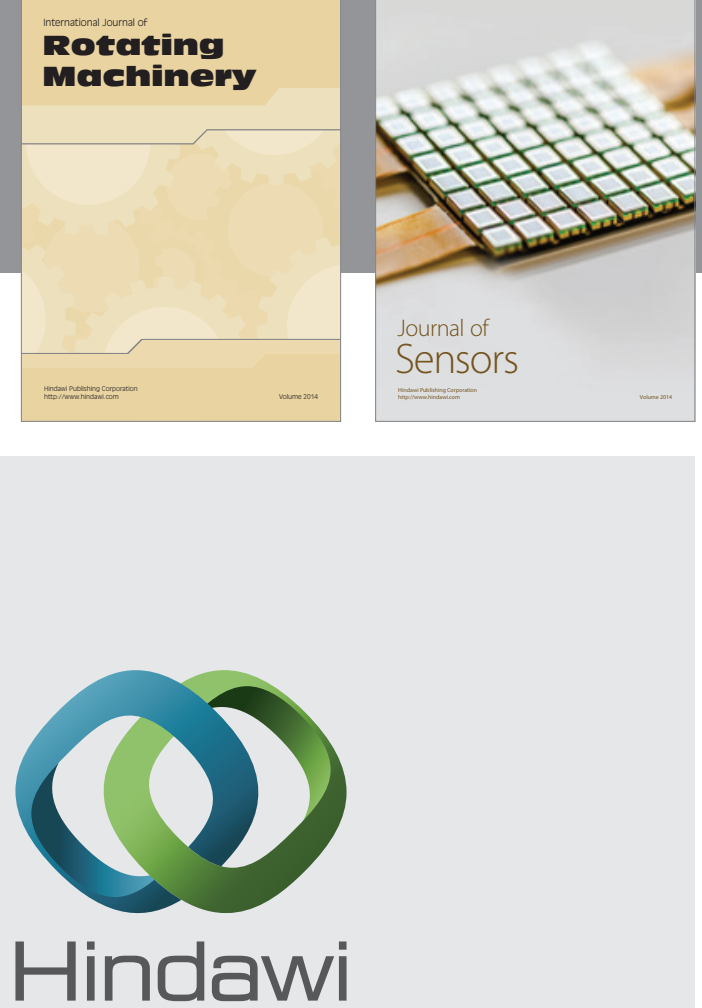

Submit your manuscripts at http://www.hindawi.com
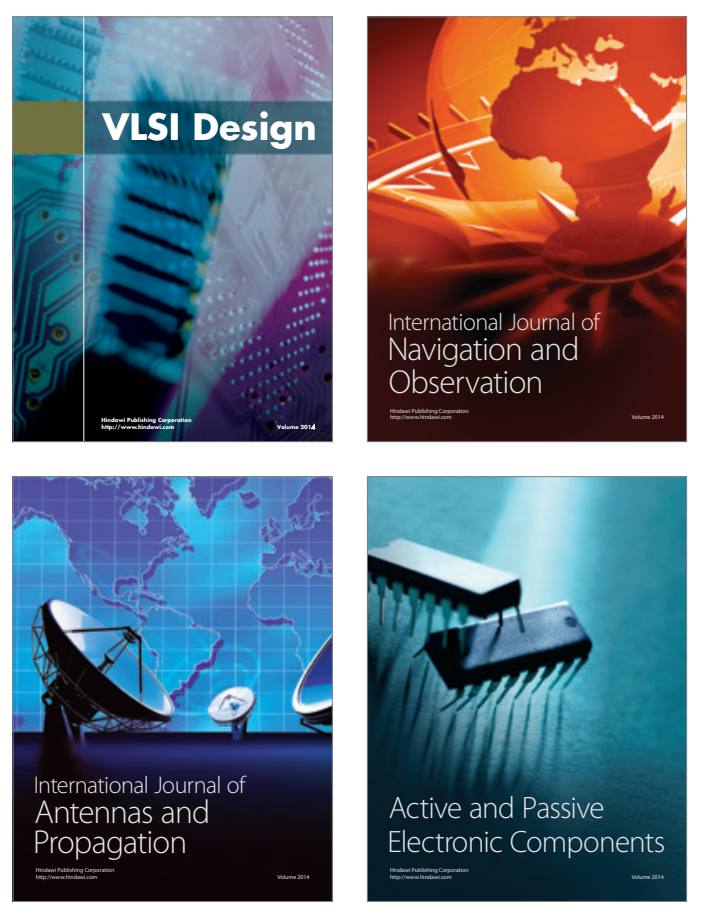
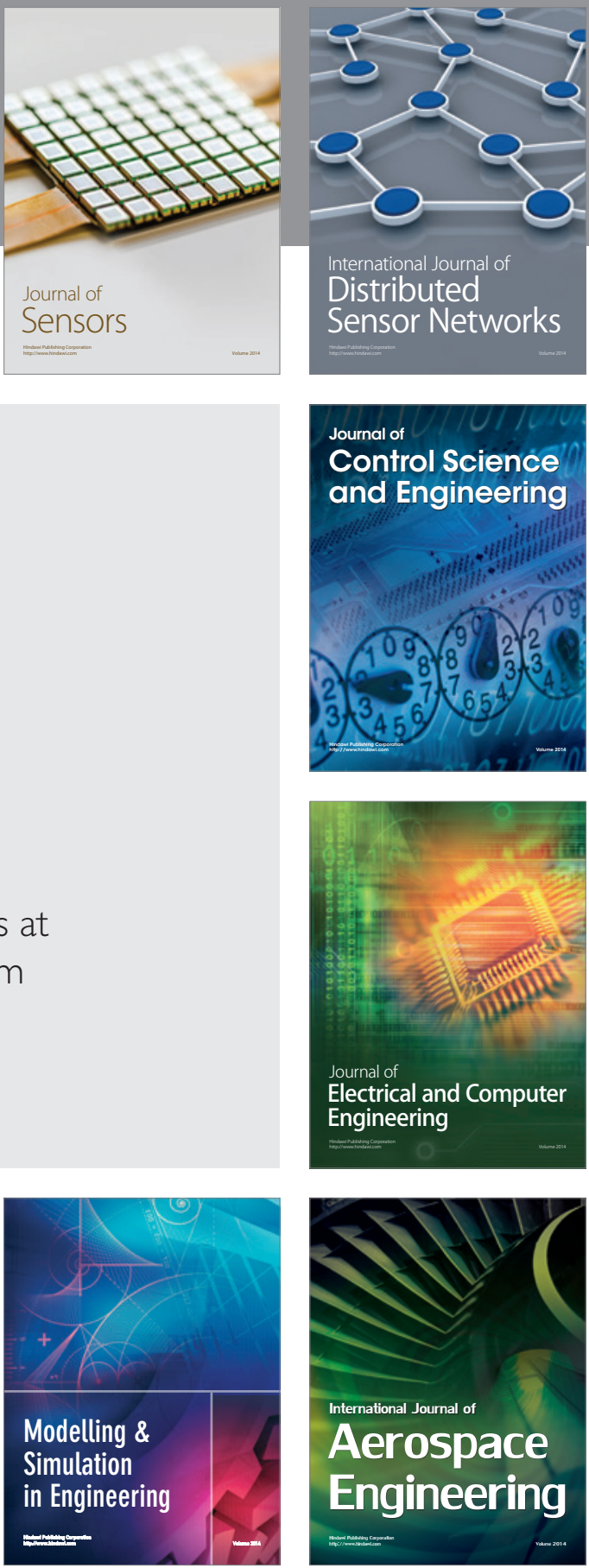

Journal of

Control Science

and Engineering
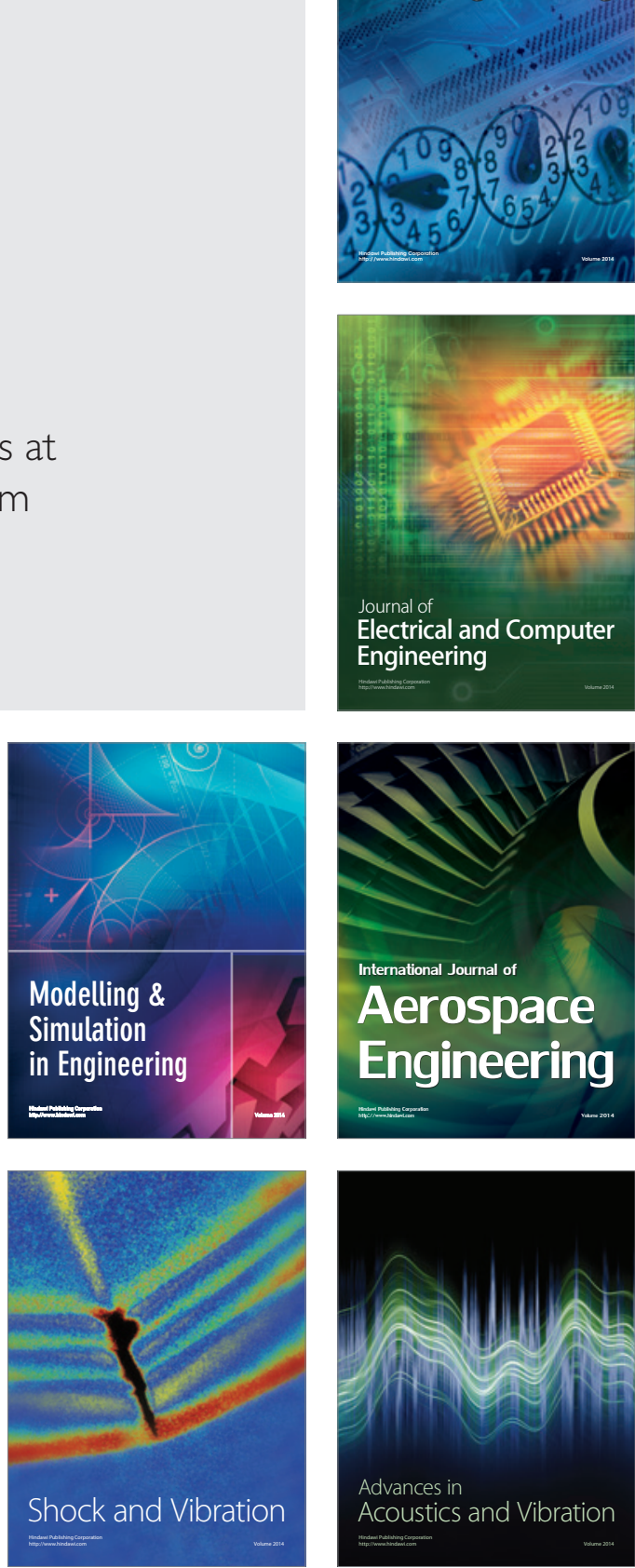